\title{
The effect of endplate preselection when measuring supine versus standing cobb angle change in idiopathic scoliosis
}

Bethany E Keenan*, Maree T Izatt, Geoffrey N Askin, Robert D Labrom, Mark J Pearcy, Clayton J Adam

From The 10th Meeting of the International Research Society of Spinal Deformities (IRSSD 2014 Sapporo)

Sapporo, Japan. 29 June - 2 July 2014

\section{Objectives}

The primary aim of this study was to determine whether endplate pre-selection makes a difference to the Cobb Angle change between supine and standing which is known to occur in idiopathic scoliosis. A secondary aim of this study was to identify which (if any) patient characteristics were correlated with supine versus standing Cobb change.

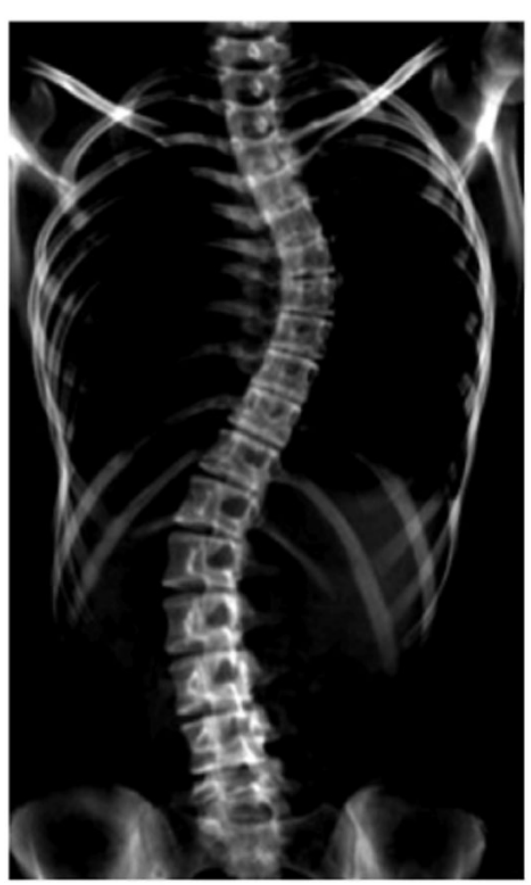

Low dose supine CT image

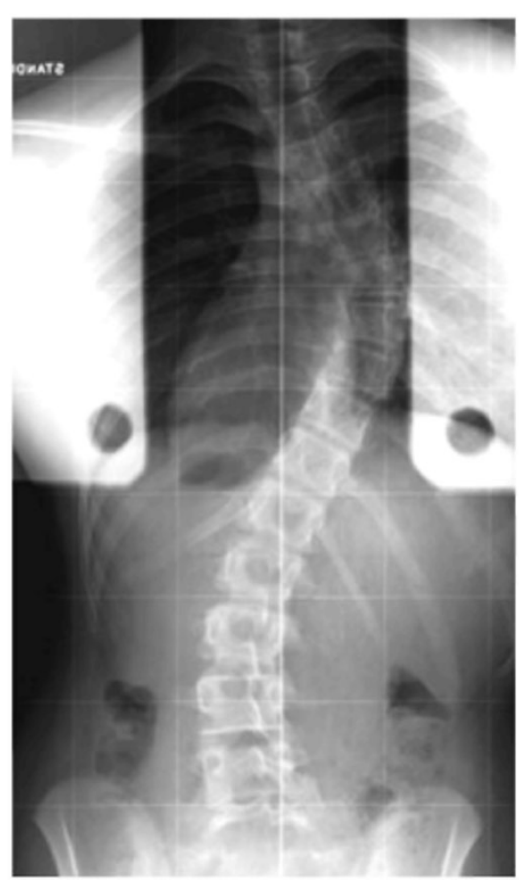

Standing radiograph

Figure 1 An example of a reformatted supine CT image Cobb $46^{\circ}$ (left) and the corresponding standing radiograph Cobb $58^{\circ}$ (right)

QUT/Mater Paediatric Spine Research Group, Institute of Health and

Biomedical Innovation, Queensland University of Technology and Mater Health Services, Brisbane, QLD, Australia 


\section{Methods}

Female Adolescent Idiopathic Scoliosis (AIS) patients with right-sided thoracic major curves were included in the retrospective study. Clinically measured Cobb Angles from existing standing coronal radiographs and fulcrum bending radiographs were compared to existing low-dose supine CT scans taken within 3 months of the reference radiograph. Reformatted coronal CT images were used to measure supine Cobb Angle variability with and without endplate pre-selection (end-plates selected on the radiographs used on the CT images). Inter and intra-observer measurement variability was assessed. Multi-linear regression to investigate whether there was a relationship between supine to standing Cobb angle change and eight variables: patient age, mass, standing Cobb angle, Risser sign, ligament laxity, Lenke type, fulcrum flexibility and time delay between radiograph and CT scan.

\section{Results}

Fifty-two patients were included, with mean age of 14.6 (SD 1.8) years; all curves were Lenke Type 1 with mean Cobb Angle on supine CT without pre-selection of endplates of $41.8^{\circ}\left(\mathrm{SD} 6.4^{\circ}\right)$ and $51.9^{\circ}$ (SD 6.7 ${ }^{\circ}$ ) on standing radiographs. The mean Cobb angle on supine $\mathrm{CT}$ images with endplate pre-selection was $40.5^{\circ}$ (SD 6.6). The mean fulcrum bending Cobb Angle for the group was $22.6^{\circ}\left(\mathrm{SD} 7.5^{\circ}\right)$. The $10^{\circ}$ increase from supine to standing is consistent with existing literature. Pre-selecting vertebral endplates was found to increase the mean signed Cobb change by $0.6^{\circ}$ (SD 2.3, range -9 to 6$)^{\circ}$. When free to do so, observers chose different levels for the end vertebrae in 39\% of cases. Multi-linear regression revealed a statistically significant relationship between supine to standing Cobb Angle change with: fulcrum flexibility $(\mathrm{p}=0.001)$, age $(\mathrm{p}=0.027)$ and standing Cobb Angle $(\mathrm{p}<0.001)$. In patients with high fulcrum flexibility scores, the supine to standing Cobb Angle change was as great as $20^{\circ}$ (Figure 1 ). The $95 \%$ confidence intervals for intra-observer and inter-observer measurement variability were $3.1^{\circ}$ and $3.6^{\circ}$, respectively.

\section{Conclusions}

Pre-selecting vertebral endplates causes minor changes to the mean supine to standing Cobb change. There is a statistically significant relationship between supine to standing Cobb change and fulcrum flexibility such that this difference can be considered a potential alternative measure of spinal flexibility.

Published: 19 January 2015
doi:10.1186/1748-7161-10-S1-043

Cite this article as: Keenan et al:: The effect of endplate preselection when measuring supine versus standing cobb angle change in idiopathic scoliosis. Scoliosis 2015 10(Suppl 1):043.
Submit your next manuscript to BioMed Central and take full advantage of:

- Convenient online submission

- Thorough peer review

- No space constraints or color figure charges

- Immediate publication on acceptance

- Inclusion in PubMed, CAS, Scopus and Google Scholar

- Research which is freely available for redistribution

Submit your manuscript at www.biomedcentral.com/submit
C Biomed Central 